\title{
Flotação com amina: a importância da qualidade da água
}

\author{
Amine flotation: the importance \\ of the water quality
}

\begin{abstract}
Viviane da Silva Pinheiro
Pesquisadora

Projeto Estruturante de C\&T Mineral-RN

viviane_vsp@yahoo.com.br
\end{abstract}

\section{Carlos Adolpho Magalhães Baltar}

Professor

Departamento de Engenharia de Minas

Universidade Federal de Pernambuco - UFPE

camb@ufpe.br

José Yvan Pereira Leite

Prof. IFRN, Coordenador

Projeto Estruturante de C\&T Mineral-RN

jyp.leite@ifrn.edu.br

\section{Resumo}

Enquanto há disponibilidade de sítios na superfície mineral, a adsorção da amina é não específica, motivada pela atração eletrostática com a superfície. Espécies catiônicas dissolvidas na água competem com o íon coletor pelos sítios negativos da superfície mineral. Esse fato evidencia a importância da composição química da água no resultado de uma flotação com amina.

Estudou-se a flotação de quartzo, com amina, usando-se três diferentes águas: (1) uma água dura proveniente de Currais Novos (Rio Grande do Norte); (2) a água de Currais Novos, após abrandamento, por meio de flotação iônica e (3) água destilada. Verificou-se a influência do $\mathrm{pH}$ e da concentração do coletor. Os testes de flotação foram realizados em Tubo de Hallimond modificado.

Os resultados mostraram que a presença dos íons cálcio e magnésio, nos níveis encontrados na água dura, prejudica a flotação com amina. A remoção parcial desses íons resultou em uma água tratada, que possibilitou um aumento na recuperação do quartzo de $32 \%$ para $86 \%$. Apesar dos cátions residuais, os resultados obtidos com a água tratada são equivalentes àqueles verificados com a água destilada, sugerindo

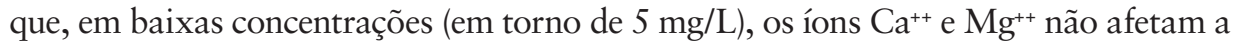
densidade de adsorção da amina na superfície do quartzo.

Palavras-chave: Água de flotação, flotação com amina, flotação de quartzo, adsorção física.

\begin{abstract}
Amine adsorption is non-specific, occurring due to electrostatic attraction with the surface. So, all cationic species dissolved in water compete with the ion by the negative sites on mineral surface. This shows the importance of water quality for amine flotation.

A quartz flotation with amine was studied using three different waters: (1) a hard water from Currais Novos (Rio Grande do Norte); (2) water from Currais Novos, after treatment by ion flotation and (3) distilled water. The $\mathrm{pH}$ and collector concentration influence were studied. The flotation tests were realized in a Hallimond Tube.

The results showed that the calcium and magnesium levels found in the hard water are detrimental for amine flotation. The removal of these ions in the treated water enabled a quartz recovery three times higher. Despite residual ions, the results with treated water are similar to those obtained with distilled water, suggesting that, in low concentrations, the $\mathrm{Ca}^{++}$and $\mathrm{Mg}^{++}$ions don't affect the amine`s adsorption density on the quartz surface.
\end{abstract}

Keywords: Hardness water in flotation, amine flotation, quartz flotation, non-specific adsorption. 


\section{Introdução}

A composição química da água é um fator determinante para o êxito de um processo de flotação. As espécies químicas dissolvidas podem afetar o resultado da flotação de diferentes maneiras (Baltar, 2010): (1) competindo com o coletor por sítios disponíveis na superfície mineral; (2) formando precipitados com o coletor; (3) promovendo a agregação de partículas finas ou (4) promovendo a ativação indesejada de minerais de ganga.

Em concentrações abaixo da formação de hemimicela, a ação das aminas caracteriza-se por uma adsorção física, não-específica, na superfície mineral (Smith e Akhtar, 1976). Isso significa que

\section{Materias e métodos}

Usou-se uma amostra de quartzo, com 96,5\% $\left(\mathrm{SiO}_{2}\right)$, proveniente da Província Borborema do Seridó. Essa amostra qual foi moída e classificada a úmido entre $149 \mu \mathrm{m}$ e $75 \mu \mathrm{m}$.

Nos testes de flotação, foram utilizadas águas com diferentes composições químicas: (a) água dura; (b) água tratada e (c) água destilada.

(a) A água dura é proveniente de um poço tubular localizado na Mineração Tomás Salustino, município de Currais Novos, no Rio Grande do Norte. O poço está localizado em região de rochas metassedimentares, com uma forte tendência de dissolução de sais na água. A água foi coletada, em bombonas de polietileno, e condicionada à temperatura ambien-

\section{Resultados e discussão}

\section{Características das águas}

Os resultados da análise química da água proveniente da mina Brejuí, com relação aos elementos cálcio e magnésio, são mostrados na Tabela 1. A água apresentou uma dureza total de $516 \mathrm{mg} . \mathrm{L}^{-1}$

\section{Flotação}

A influência da qualidade da água está relacionada à competição, entre as espécies catiônicas e a amina, pelos sítios disponíveis na superfície mineral. Os resultados da flotação são mostrados nas Figuras 1 e 2.

Considerando-se que a adsorção da amina depende dos sítios negativos qualquer espécie catiônica dissolvida na água compete com a amina pelos sítios disponíveis, resultando em uma menor densidade de adsorção do coletor (Baltar \& Cunha, 2002; Pinheiro, 2011).

Diversos autores observaram a influência negativa de espécies catiônicas dissolvidas na água na flotação com amina. Em trabalhos distintos, Rao et al. (1988) e Espinosa-Gomes et al. (1987) tiveram problemas na flotação de pirocloro com uma água reciclada, só conseguindo bons resultados após a remoção dos íons $\mathrm{Ca}^{++}$. O efeito depressor de espécies catiônicas, na flotação de feldspato, com amina foi observado por

te, no Laboratório de Processamento Mineral e de Resíduos (LPMR) do IFRN. Algumas análises físico-químicas foram realizadas de imediato ( $\mathrm{pH}$ e condutividade), enquanto outras análises foram feitas num período inferior a quatro dias. Foram realizadas análises de rotina (dureza total, cálcio, magnésio, $\mathrm{pH}$ e condutividade), para acompanhar possíveis alterações na qualidade da água.

(b) A água tratada é resultado da eliminação parcial dos cátions $\mathrm{Ca}^{++} \mathrm{e} \mathrm{Mg}^{++}$, da água de Currais Novos, por meio de uma flotação iônica, com oleato de sódio, em célula FAD (Flotação por Ar Dissolvido).

(c) A água destilada foi obtida em destilador de laboratório.
Baltar e Cunha (2002).

O trabalho teve por objetivo comparar os resultados da flotação de quartzo quando realizada com água dura, água tratada e água destilada. Usou-se uma água com elevado teor de cálcio e magnésio, obtida de um poço de uma antiga Mina de Scheelita, no município de Currais Novos (Rio Grande do Norte).

$\mathrm{O}$ tratamento dessa água dura, feito por meio de flotação por ar dissolvido (FAD), com oleato de sódio, produziu uma água cujas características proporcionaram resultados na flotação semelhantes àqueles obtidos com água destilada.

Nos testes de flotação, foi utilizada uma dodecilamina comercial, da Azko Nobel, neutralizada com ácido clorídrico. A correção do $\mathrm{pH}$ foi feita com hidróxido de sódio $(\mathrm{NaOH})$ ou ácido clorídrico $(\mathrm{HCl})$. Todos os reagentes utilizados, na flotação, são de natureza analítica. Os ensaios de microflotação foram realizados em tubo de Hallimond modificado, com 1g de quartzo, e fluxo de ar foi mantido em $40 \mathrm{~mL} \cdot \mathrm{min}^{-1}$. Os ensaios foram realizados em triplicata.

A caracterização físico-química da água foi realizada pelo método usado para análise química de dureza total via titulação complexométrica com EDTA (Apha et al., 2005).
$\mathrm{CaCO}_{3}$, caracterizando-se como uma água de elevada dureza.

Após a eliminação parcial das espécies catiônicas por flotação iônica em célula FAD, obteve-se a água tratada, com dureza total de apenas $30 \mathrm{mg} \cdot \mathrm{L}^{-1} \mathrm{CaCO}_{3}$. A composição química, com relação aos elementos cálcio e ao magnésio, é mostrada na Tabela 2. A Tabela 3 apresenta os teores de $\mathrm{Ca}^{++}$e $\mathrm{Mg}^{++}$da água destilada. disponíveis na superfície mineral e que, portanto, só pode ocorrer acima do ponto isoelétrico, a faixa de $\mathrm{pH}$ levemente alcalina é a mais favorável para a hidrofobização da superfície. Em meio muito alcalino, apesar da maior disponibilidade de sítios negativos, a relação $\mathrm{RNH}_{3}{ }^{+}$| $\mathrm{RNH}_{2}$ diminui, progressivamente, resul- tando em baixos valores de recuperação (Baltar, 2010).

Os resultados apresentados na Figura 1 evidenciam a importância da qualidade da água em flotação com amina e confirmam a faixa de $\mathrm{pH}$ levemente alcalina como a mais favorável. Em pH 8 , por exemplo, a recuperação de quart- 
Tabela 1

Concentração de espécies catiônicas na água de Currais Novos.

Tabela 2

Concentração de espécies catiônicas na água tratada.

Tabela 3

Concentração de espécies catiônicas na água destilada.

Figura 1

Influência da qualidade da água na flotação de quartzo com dodecilamina $(400 \mathrm{~g} / \mathrm{t})$.

zo é de 90,1\%, 91,4\% e 80,7\%, respectivamente, para a água destilada, a água tratada e a água dura, com alto teor de cálcio e magnésio.

À medida que aumenta a alcalinidade da polpa, cresce a influência dos cátions $\mathrm{Ca}^{++}$e $\mathrm{Mg}^{++}$, presentes na água dura, devido à redução da concentração da espécie $\mathrm{RNH}_{3}{ }^{+}$responsável pela adsorção do coletor na superfície do quartzo. A recuperação obtida em água dura,

Figura 2

Efeito da concentração de dodecilamina da flotação de quartzo, em pH 8, para os diferentes tipos de água.

\begin{tabular}{c|c}
\hline Elemento & Concentração, $\mathbf{m g} \cdot \mathbf{L}^{-1}$ \\
\hline Cálcio, $\mathrm{Ca}^{++}$ & 93 \\
\hline Magnésio, $\mathrm{Mg}^{++}$ & 69 \\
\hline \multicolumn{2}{|c}{} \\
\hline Elemento & Concentração, $\mathbf{m g} \cdot \mathrm{L}^{-1}$ \\
\hline Cálcio, $\mathrm{Ca}^{++}$ & 4,08 \\
\hline Magnésio, $\mathrm{Mg}^{++}$ & 4,82 \\
\hline & \\
\hline Elemento & Concentração, $\mathbf{m g} \cdot \mathrm{L}^{-1}$ \\
\hline Cálcio, $\mathrm{Ca}^{++}$ & 2,90 \\
\hline Magnésio, $\mathrm{Mg}^{++}$ & 0,87 \\
\hline
\end{tabular}

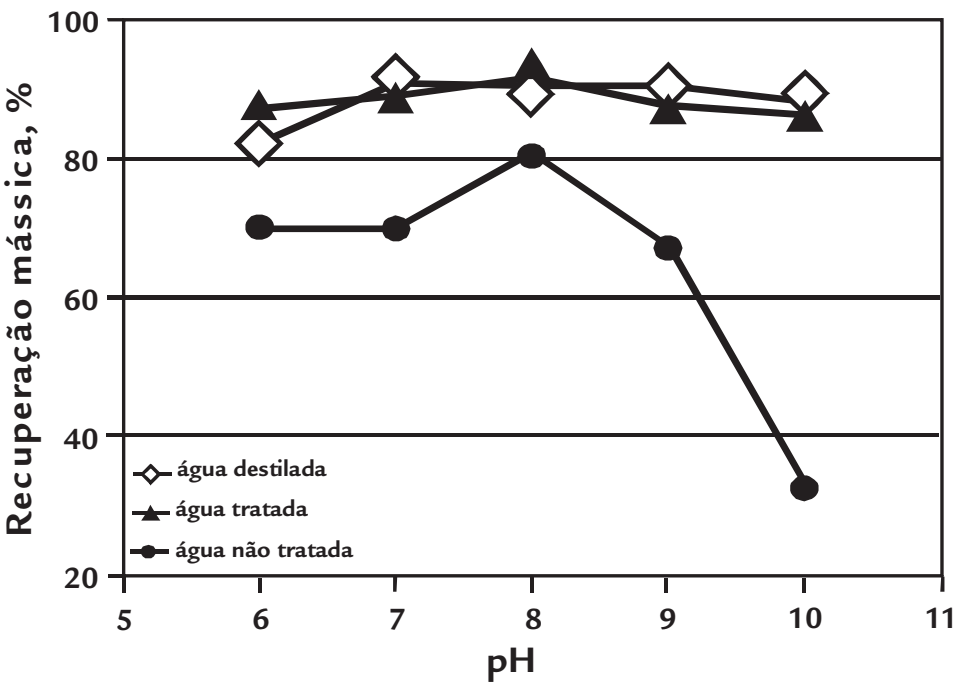

em $\mathrm{pH} 10$, foi de apenas $32 \%$.

Considerando-se que a influência da composição química da água está relacionada com a competição das espécies catiônicas, pelos sítios negativos da superfície mineral, procurou-se verificar a influência da concentração do coletor em $\mathrm{pH} 8$, onde há uma menor quantidade de sítios negativos na superfície do quartzo se comparado com o pH 10. Os resultados são apresentados na Figura 2.
De acordo com os resultados da Figura 2, o efeito prejudicial da presença de espécies catiônicas na água poderia ser amenizado com o aumento da concentração do coletor. Deve-se considerar, no entanto, que isso implica maior consumo do reagente e aumento da intensidade de espumação, que pode atingir níveis que comprometem o controle operacional.

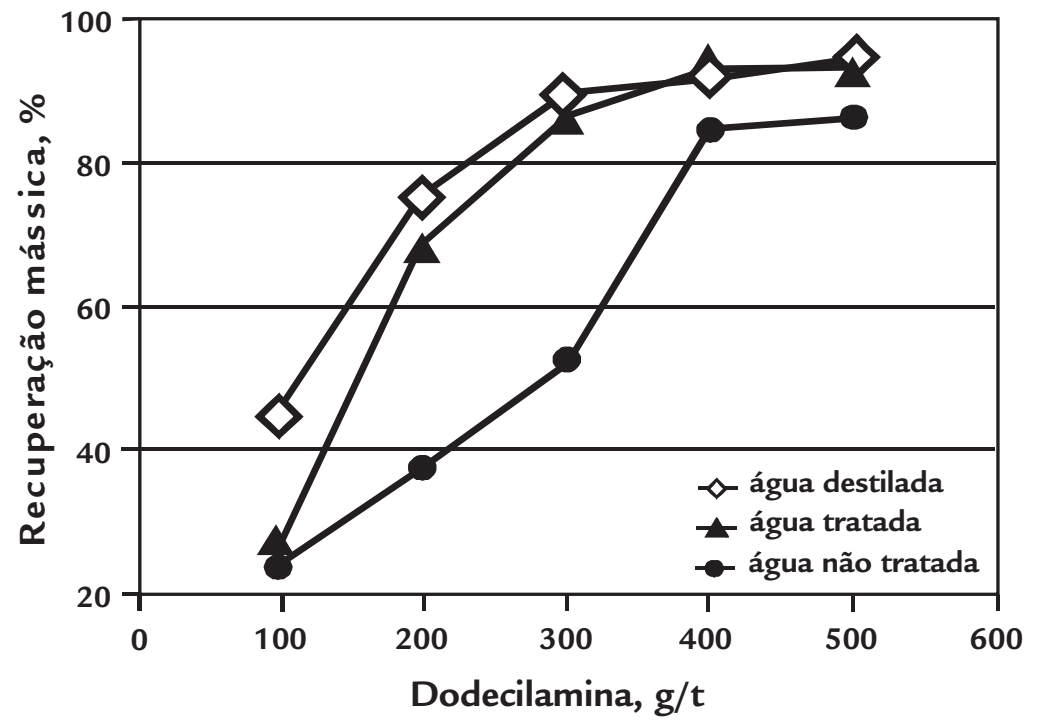




\section{Conclusões}

Comparou-se a recuperação de quartzo obtida com água dura, água tratada e água destilada. O tratamento da água dura, feito por flotação por ar dissolvido (FAD), produziu uma água com baixa concentração de íons cálcio e magnésio.

Os resultados mostraram a importância da composição da água na flotação com amina. As maiores recuperações

\section{Agradecimentos}

Os autores do trabalho expressam os agradecimentos ao CNPq - FINEP, FAPERN (Projeto Fortalecimento da

Estrutura de Apoio a Pesquisa para APL mineral do Rio Grande do Norte) pelo financiamento desse trabalho e ções significativas na densidade de adsorção da amina, na superfície do quartzo.

A influência da composição química da água é mais evidente para baixas concentrações de coletor e elevados valores de $\mathrm{pH}$. Com $400 \mathrm{~g} / \mathrm{t}$ de amina, em pH 10 , a recuperação de quartzo com água dura cai para cerca de $1 / 3$ daquela obtida com água tratada. $\mathrm{O}$ mesmo acontece, com $200 \mathrm{~g} / \mathrm{t}$ do coletor, em pH 8.

concessão da bolsa de Desenvolvimento Tecnológico Industrial (DTI-3) de Viviane Pinheiro.

\section{Referências bibliográficas}

APHA, AWWA, WEF. Standard Methods for the Examinations of Water and Wastewater. American Public Associations. 21th Washington DC. 2005

BALTAR, C. A. M. Flotação no tratamento de minérios. $2^{a}$ Edição. Recife: Editora Universitária da UFPE, 2010. 238 p.

BALTAR, C. A. M., CUNHA, A. S. F. Influência de espécies catiônicas na flotação de feldspato com amina. In.: BALTAR, C. A. M., BARBOSA, J. P., OLIVEIRA, J. C. S. (editores). ENCONTRO NACIONAL DE TRATAMENTO DE MINÉRIOS E METALURGIA EXTRATIVA, Anais... Recife, 2002. p. 234-240.

ESPINOSA-GOMES, R., FINCH, J. A., LAPLANTE, A. R. Effects of the type of water on the selective flotation of pyrochlore from niobec. Colloids and Surfaces, v. 26, p. 333-350, 1987.

PINHEIRO, V. S. Aplicação de flotação por ar dissolvido para tratamento de águas duras da região Seridó/RN. Pernambuco: Programa de Pós-Graduação em Engenharia Mineral da Universidade Federal de Pernambuco, 2011. 63 p. (Dissertação de Mestrado).

RAO, S. R., ESPINOSA-GOMEZ, R., FINCH, J. A., BISS, R. Effects of water chemistry on the flotation of pyrochlore and silicate minerals. Minerals Engineering, v. 1, n.3, p. 189-202, 1988.

SMITH, R.W., AKHTAR, S. Cationic flotation of oxides and silicates. In.: Flotation. A.M. Gaudin Memorial Volume, Fuerstenau, M.C. (Editor). Society of Mining Engineers, v. 1. p. 87-116, 1976.

Artigo recebido em 17 de junho de 2011. Aprovado em 08 de setembro de 2012. 